\title{
Síndrome de McCune-Albright en un adolescente. Informe de un paciente
}

\author{
McCune-Albright syndrome in an adolescent youngster
}

Guillermo Uribe González,* Luis Sigler Morales**

Palabras clave: Síndrome de McCune-Albright, adolescente varón, alopecia areata.

Key words:

McCune-Albright syndrome, adolescent male, alopecia areata.

\footnotetext{
* Cirujano General.

** Expresidente de la

Asociación Mexicana de Cirugía General.
}

\section{RESUMEN}

Introducción: Éste es un síndrome muy raro, no hereditario, aparente desde el nacimiento o juventud, identificado clínicamente por displasia ósea, manchas en la piel y pubertad precoz; es originado por alteración del cromosoma 20. El objetivo de este trabajo es presentar el caso de un adolescente que acudió a consulta por una úlcera en la planta de un pie; tenía, además, manifestaciones de este síndrome. Caso clínico: Joven de 16 años que radicaba en una población rural alejada; acudió a consulta por presentar una úlcera en la planta del pie derecho, de varios meses de evolución. Tenía acortamiento de la extremidad inferior derecha, manchas de color café con leche en diversas partes del cuerpo, evidencia de desarrollo anormal de las extremidades y una zona de alopecia areata en la cabeza. Se le dieron indicaciones respecto a la úlcera del pie con el uso de aseo, vendas, plantilla para elevar el pie, y se le ofreció una cita para indicar otros estudios y referencia a otros especialistas, pero no regresó. Posteriormente, con su familia, cambió de domicilio. Los hallazgos a la exploración permitieron establecer el diagnóstico clínico de síndrome de McCune-Albright.

\section{ABSTRACT}

Introduction: This is a non-hereditary, very rare syndrome, present since birth or youth; it is due to an alteration in the chromosome 20. The objective of this work is to present the case of a male adolescent who consulted because of an ulcer in the sole of the right foot; he also showed signs of this syndrome. Case report: 16-year-old male who lived in a distant rural zone; he complained of an ulcer in the sole of the right foot for several months. There was shortness of the right lower extremity, cafe-au-lait pigmented skin lesions, abnormal development of limbs and alopecia areata of the scalp. Cleaning of the ulcer, bandages, sole protector, and rest were recommended. A future work-up with $X$ rays and consultations was planned, but he never came back. Later, he changed his address. Clinical findings were the basis of the diagnosis of McCune-Albright syndrome.

\section{INTRODUCCIÓN}

E n los años 30, McCune, y un año más tarde, Albright, presentaron pacientes con ciertas características: displasia fibrosa de uno o varios huesos, manchas de color café con leche en el cuerpo y pubertad precoz. ${ }^{1,2}$ Posteriormente, se identificó a estos enfermos como portadores del síndrome que lleva sus nombres. De un modo progresivo, se fueron agregando otras condiciones como exceso de hormona del crecimiento, eliminación renal anormal de fosfato con o sin raquitismo/osteomalacia, síndrome de Cushing y, rara vez, la participación de otros órganos y sistemas como el cerebro, ojos, dientes, hígado, corazón, paratiroides o páncreas.
Este síndrome es una condición rara y no hereditaria. En nuestro país, sólo hemos encontrado tres comunicaciones al respecto. ${ }^{3-5}$ Aunque no se cuenta con datos de prevalencia disponibles, se ha comentado que puede ocurrir en rangos que van de 1/100,000 a 1/1,000,000. Los estudios genéticos de las Ilamadas proteínas $\mathrm{G}$, relacionadas con el desarrollo de los tejidos musculoesqueléticos y hormonales, han permitido identificar que las alteraciones genéticas están en el brazo largo del cromosoma 20 (20q13.2), en el gen denominado GNAS1. Existe mutación en mosaicismo, al azar en todas o sólo algunas células. Además, no es hereditaria y los pacientes sufren displasia fibrosa, causa de malformaciones óseas en diversos sitios. ${ }^{6,7}$ 
Nuestro objetivo es presentar los hallazgos clínicos de un adolescente que acudió a consulta por una lesión en la planta de un pie y tenía manifestaciones de este síndrome.

\section{CASO CLÍNICO}

Un joven de 16 años se presentó a consulta acompañado por un familiar, por una úlcera de unos ocho meses de evolución en la parte posterior de la planta del pie derecho, dolorosa y que no había cedido a cuidados generales. Desde niño tuvo la extremidad inferior derecha más corta y delgada que la izquierda, lo que motivó una marcha irregular. Desde que nació tenía manchas en el cuerpo, que también se extendían a ambas piernas. Por varios años, había notado que en casi tres cuartas partes de la cabeza no tenía cabello, por lo que todo el tiempo usaba una gorra.

A la exploración, se encontró a un joven en buenas condiciones generales, con gorra puesta. Peso: $61 \mathrm{~kg}$, estatura: $1.65 \mathrm{~m}$. Tensión arterial, normal. La marcha, difícil por apoyar la parte delantera del pie derecho e inclinar el tronco hacia afuera. El tórax derecho, cubierto por piel con una mancha color café que se extendía hasta el pie y hacia el brazo. En el lado izquierdo también había mancha, pero en menor proporción, aunque distalmente se extendía hasta el talón. No se apreciaron anomalías a la auscultación del tórax o al examen del abdomen. La extremidad inferior derecha era más delgada y corta que la izquierda. En la planta del pie derecho tenía una úlcera de $11 \times 6 \mathrm{~cm}$, localizada en la mitad posterior del pie, con bordes eritematosos y evidencia de sangrado superficial. No se apreciaron huesos o tendones expuestos. Los pulsos periféricos eran normales. Durante el examen se apreció un crecimiento de los genitales externos; el paciente no refirió dolor. Al retirar la gorra se apreció una zona de alopecia que abarcaba las dos terceras partes del cuero cabelludo (Figuras 1 a 5).

Se le efectuó aseo de la úlcera y se le colocó un vendaje acolchonado suave. Se le dieron indicaciones para el cuidado de la úlcera, la colocación de vendaje suave y la obtención de una plantilla especial para evitar la presión en esa zona. Se le dio una nueva cita, a la que no acudió. Cuando la asistente llamó al teléfono que habían dejado, informaron que ya se habían cambiado de domicilio e ignoraban la nueva dirección.

\section{DISCUSIÓN}

De una manera clásica, se define al síndrome de McCune-Albright por la tríada clínica de displasia fibrosa de hueso, manchas café con leche en el cuerpo y pubertad precoz. ${ }^{6}$ Las alteraciones óseas pueden afectar uno o varios huesos y presentarse con dolor o trastornos para caminar, con o sin fractura. Tiene cierto predominio en pacientes del sexo femenino, en quienes se manifiesta por sangrado vaginal o crecimiento de mamas; en los hombres puede haber crecimiento genital y conducta sexual precoz. Si hay otras endocrinopatías, puede haber manifestaciones tiroideas, en el crecimiento - como un síndrome de Cushing-y eliminación anormal por vía renal de fosfato, entre otros. ${ }^{7}$ En la cabeza pueden existir manifestaciones oftálmicas, auditivas o esqueléticas de severidad variable. Salenave y sus colaboradores revisaron 112 pacientes y señalaron que la acromegalia está presente en el 20 a 30\% de quienes padecen de este síndrome y tienen las características particulares de diagnóstico y tratamiento. ${ }^{8}$ Hasta donde sabemos, éste es el primer informe de alopecia areata asociada a este síndrome.

El tratamiento es muy variado, depende de la edad del paciente y los órganos involucrados, pero es indudable que se requiere de la participación de un equipo con múltiples especialistas, pediatras, radiólogos, internistas, cirujanos, ortopedistas, genetistas, dermatólogos, oftalmólogos, endocrinólogos y otros, según el caso. En cada especialidad, el médico asignado será el encargado de otorgar el abordaje necesario. ${ }^{9}$ Así, aunque no hay tratamiento para la displasia fibrosa de los huesos, el ortopedista se enfocará en optimizar la función y minimizar la morbilidad debida a fracturas y deformidades. Para atender la precocidad sexual, el ginecólogo puede usar el letrozole y un receptor como el tamoxifén; en hombres jóvenes, las opciones no están establecidas. En un estudio de 54 varones con síndrome de McCune-Albright, Boyce y su grupo encontraron como hallazgo 
histopatológico predominante la hiperplasia de las células de Leydig. ${ }^{10}$

El metimazole mejora las condiciones de hipertiroidismo persistente, aunque se puede requerir la tiroidectomía. Para mejorar el exceso de hormona del crecimiento, se puede recurrir al octreótido y a un antagonista del receptor de la hormona del crecimiento, como el pegviso-

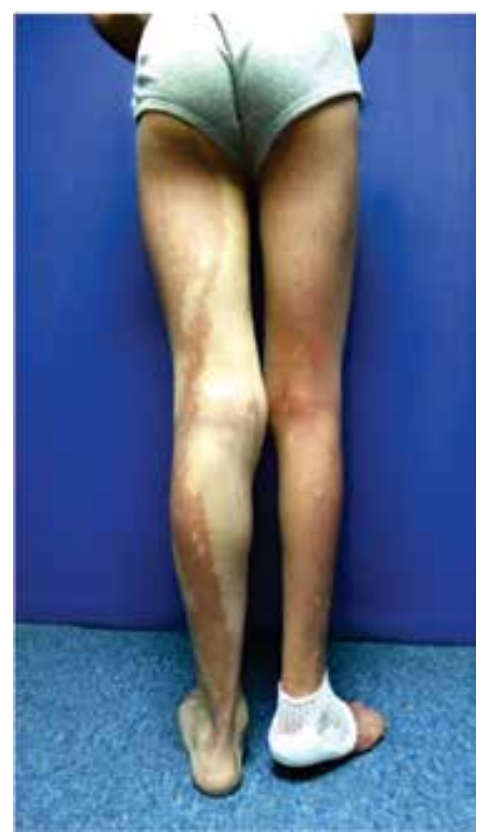

Figura 1.

Vista posterior de las extremidades inferiores. La mancha café se extiende hasta los pies.

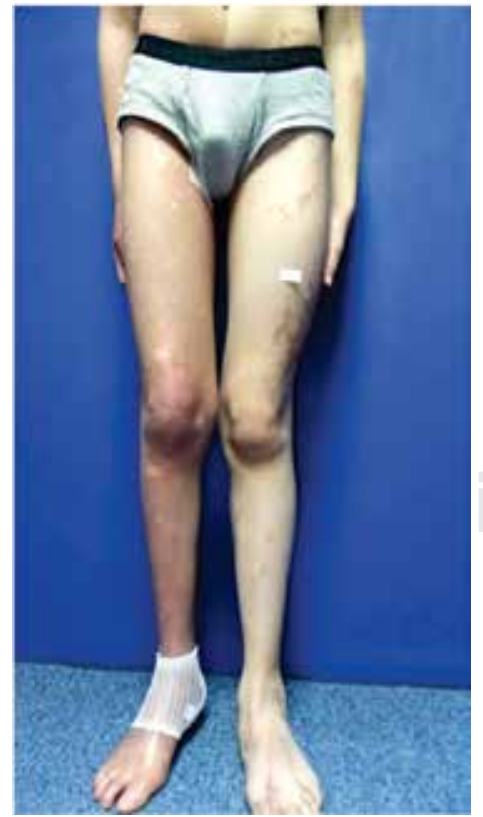

Figura 2.

Acortamiento y adelgazamiento del miembro inferior derecho, con manchas hasta el pie. En el lado izquierdo se aprecian algunas manchas.

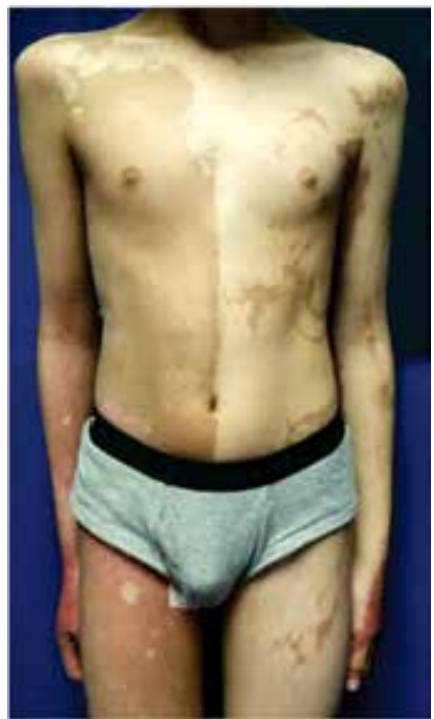

Figura 3.

Manchas café con leche de predominio en la mitad derecha del tórax y abdomen, y que se extienden hacia el muslo. En el lado izquierdo también existen manchas. Se aprecia un aumento del tamaño de los genitales externos.

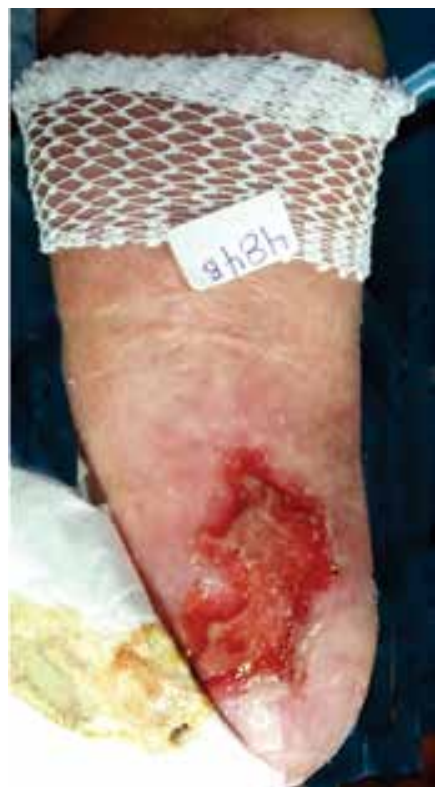

Figura 4.

Úlcera que ocupa casi la totalidad del tercio distal del talón derecho.

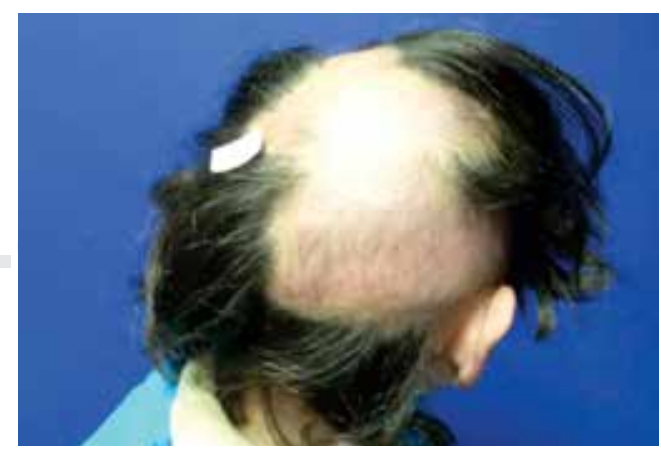

Figura 5. Se aprecia alopecia en la mitad de la superficie craneal. 
mant. Se deben hacer estudios de la columna vertebral para descartar escoliosis progresiva. Es recomendable evitar deportes y actividades que puedan comprometer a los huesos.

En hombres, se deben evaluar las características genitales y vigilar con ultrasonido testicular, con la participación activa de urólogos interesados. Es útil vigilar los niveles de fósforo para observar la hipofosfatemia. Casi cada año se debe obtener evaluación ocular y otológica y tomografía del cráneo para vigilar el estado de displasia ósea en esa zona, con afección funcional. En ocasiones, es necesario descomprimir alguna presión sobre el nervio óptico. ${ }^{11}$ Puede requerirse la participación de cirujanos reconstructivos y odontólogos capacitados para corregir deformaciones orofaciales. Pichard y sus colegas informaron de cuatro pacientes con este síndrome que, además, tenían pigmentación de la mucosa oral en la infancia o juventud. ${ }^{12}$

En el caso aquí presentado, sus condiciones socioeconómicas evitaron que regresara a consulta para continuar su estudio y tratamiento, pero fue posible integrar el síndrome de McCune-Albright con las características clínicas. $6,12,13$

\section{REFERENCIAS}

1. McCune D. Osteitis fibrosa cystica: the case of a nineyear-old girl who also exhibits precocious puberty, multiple pigmentation of the skin and hyperthyroidism. Am J Dis Child. 1936; 52: 743-744.

2. Albright F, Butler AM, Hampton AD, Smith P. Syndrome characterized by osteitis fibrosa disseminate areas of pigmentation and endocrine dysfunction with precocious puberty in females. N Eng J Med. 1937; 216: 726-746.

3. Ordaz-Favila JC, Guerra-Marín BJ, Salazar-León JA, Fernández-Álvarez H. Síndrome de McCune-Albright:
Revisión de la literatura y presentación de un caso. Rev Mex Oftalmol. 2000; 74: 29-33.

4. López-Parra A, Hernández SM, Zárate-Méndez A. Displasia fibrosa y síndrome de McCune-Albright. Arch Neurocien Mex. 2006; 11: 41-46.

5. Salas-López EK, Martínez AE. Tratamiento integral odontopediátrico del paciente con síndrome de McCune-Albright. Reporte de un caso. Rev AMOP. 2007; 19: 40-49.

6. Lietman SA, Schwindinger WF, Levine MA. Genetic and molecular aspects of McCune-Albright syndrome. Pediatr Endocrinol Rev. 2007; 4 Suppl 4: 380-385.

7. Dumitrescu CE, Collins MT. McCune-Albright syndrome. Orphanet J Rare Dis. 2008;3:12.

8. Boyce AM, Collins MT. Fibrous dysplasia/McCuneAlbright syndrome. In: Pagon RA, Adam MP, Ardinger $\mathrm{HH}$, Wallace SE, editors. Gene reviews [Internet]. Seattle (WA): University of Washington, Seattle; 19932016. 2015 Feb 26.

9. Salenave S, Boyce AM, Collins MT, Chanson P. Acromegaly and McCune-Albright syndrome. J Clin Endocrinol Metab. 2014; 99: 1955-1969.

10. Collins MT, Singer FR, Eugster E. McCune-Albright syndrome and the extraskeletal manifestations of fibrous dysplasia. Orphanet J Rare Dis. 2012; 7 Suppl 1: S4.

11. Boyce AM, Chong WH, Shawker TH, Pinto PA, Linehan WM, Bhattacharryya $\mathrm{N}$, et al. Characterization and management of testicular pathology in McCuneAlbright syndrome. J Clin Endocrinol Metab. 2012; 97: E1782-E1790.

12. Pichard DC, Boyce AM, Collins MT, Cowen EW. Oral pigmentation in McCune-Albright syndrome. JAMA Dermatol. 2014; 150: 760-763.

13. Boyce AM, Glover M, Kelly MH, Brillante BA, Butman JA, Fitzgibbon EJ, et al. Optic neuropathy in McCuneAlbright syndrome: effects of early diagnosis and treatment of growth hormone excess. J Clin Endocrinol Metab. 2013; 98: E126-E134.

Correspondencia:

Dr. Guillermo Uribe González

Centro Médico del Noroeste.

Boulevard Sánchez Taboada 1527-205,

Zona Río, Tijuana, BC.

Teléfono: (664) 684-8127

E-mail: drguribe@hotmail.com 